\title{
UM SISTEMA DE NOTIFICAÇÃO INTELIGENTE
}

\author{
An Intelligent Student Notification System
}

\author{
Mariana de Souza ${ }^{1}$ \\ Fabio Yoshimitsu Okuyama²
}

\begin{abstract}
Resumo: Com a modalidade da Educação a Distância (EaD), o conhecimento tornou- se mais acessível devido à facilidade de ingresso do aluno na instituição pretendida, ao tempo e local de estudos de que dispõem. No entanto, a grande quantidade de alunos que a modalidade permite atender implica, também, na necessidade de acompanhar e avaliar o ensino na mesma proporção em que é ofertado. Neste contexto, a tutoria tem papel fundamental nesse processo, apesar de enfrentar grande dificuldade na manutenção dessa prática. Visando contribuir para minimizar esta dificuldade, foi idealizado um Modelo de Notificação Inteligente, desenvolvido para atuar em cursos abertos, estimulando os estudantes, por meio do envio de mensagens automatizadas e personalizadas, a concluírem os cursos. O objetivo é atenuar a alta taxa de evasão que permanece no cenário da $\mathrm{EaD}$ a partir de uma metodologia de notificação inteligente que considerou o perfil do aluno como base para seu desenvolvimento, no sentido de rendimentos acadêmicos e de predileções pessoais, culminando em mensagens interativas altamente personalizadas. SINTA, o modelo de notificação inteligente, foi delineado e aplicado, parcialmente, em um curso aberto, obtendo duas leituras de retorno positivo: $40 \%$ com alunos que corresponderam ativamente e $20 \%$ de correspondência no grande grupo com alunos de perfis variados, determinando as contribuições possíveis e positivas que correspondem satisfatoriamente ao objetivo da pesquisa.
\end{abstract}

Palavras-chave: Notificação inteligente. Perfil do aluno. Cursos abertos.

Abstract: From the growth of the Distance Education modality, the access to knowledge became more accessible due to the ease of admission, wide range of themes and the student autonomy in the process, regarding the possibility of choosing time and place to study. However, the massive number of students that the modality allows to attend, also implies the need to monitor and evaluate the teaching in the same proportion that is offered. In such a context, tutoring has a fundamental role in this process despite facing great difficulty in sustaining this practice. Aiming to provide means to reduce such difficulty, the intelligent notification model was designed to work in open courses, encouraging students, by sending automated and personalized messages to complete the courses. The objective is to mitigate the considered dropout rate that remains in the distance education modality based on the intelligent tutoring methodology that took into account the student's profile as a basis for development, in the sense of academic performance and personal predilections, culminating in highly interactive and personalized phrases. SINTA, the intelligent notification model, was designed and applied partially in an open course, obtaining two positive feedback readings: $40 \%$ with students who actively corresponded and $20 \%$ of correspondence in the large group with

\footnotetext{
${ }^{1}$ Mariana de Souza é graduada em Pedagogia e Mestre pelo Mestrado Profissional em Informática na Educação (IFRS). E-mail marihfill@gmail.com; Orcid https://orcid.org/0000-0002-5375-0062

${ }^{2}$ Fabio Y. Okuyama é Bacharel (UEL), Mestre e Doutor (UFGRS) em Ciência da Computação, docente no IFRS - Campus Porto Alegre. E-mail fabio.okuyama@ poa.ifrs.edu.br. Orcid https://orcid.org/0000-0001-7427-2525
} 
students of varied profiles, determining the possible contributions and positive results that satisfactorily correspond to the research objectives.

Keywords: Intelligent Notification System. Profile of the student. Open courses.

\section{Introdução}

À luz da observação, percebe-se que as deficiências do ensino presencial se assemelham àquelas que se fazem presentes, também, na modalidade de Educação a Distância (EaD), sobretudo no que diz respeito à evasão. No Relatório Analítico da Aprendizagem a Distância no Brasil, determinado no mais recente Censo da Associação Brasileira de Educação a Distância (ABED) de 2018, embora haja aumento de interessados nos cursos ofertados na modalidade de educação a distância, conforme nos mostra o Gráfico 1, a seguir, essencialmente por razões que possibilitem maior acesso e preparo para o mercado de trabalho, os índices de evasão são, ainda, uma grande preocupação revelada na pesquisa.

Gráfico 1 - Matrículas em cursos a distância no Brasil, por modalidade

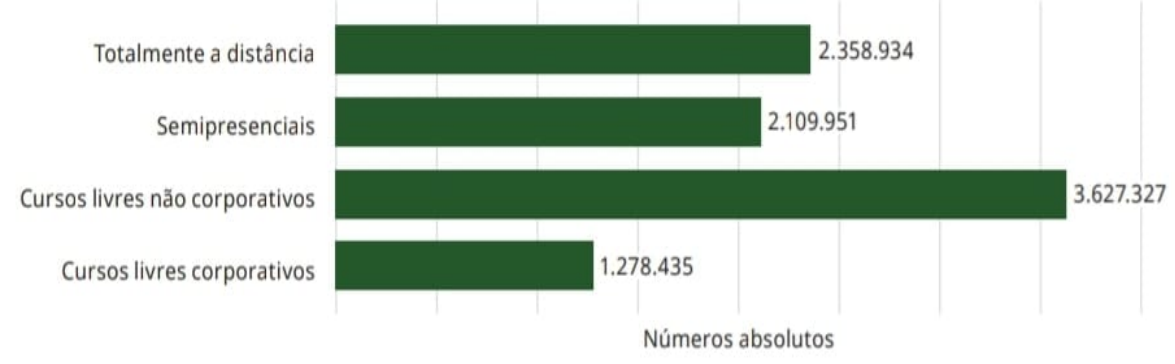

Fonte: Censo ABED (2018, p.62).

Com o advento das tecnologias em geral, a educação passou a ter maior oferta, e também maior acesso, promovendo, na prática, a ideologia que se refere "à democratização do ensino". Embora nem todos possam, ainda, usufruir dessas tecnologias, por questões das desigualdades sociais - aspecto que foge da abordagem aqui pretendida -, tal formato de ensino cresce a cada dia, trazendo também, muitas complexidades.

Tendo em vista que a EaD e sua característica ubíqua relativizam tempo e espaço ao colocar alunos em constante interação uns com os outros ou com as informações que geram o conhecimento por meio de variadas tecnologias, é fortalecida a premissa de que tal modalidade de ensino revoluciona a forma de promover a educação, atraindo novos e muitos olhares para a possibilidade de estudar e adequando-se às demandas e eventualidades que antes eram impedimentos.

Apesar de demonstrar vantagem na busca por estudantes, conforme índices expostos no Gráfico 1, mostrado anteriormente, o ensino na modalidade a distância apresenta taxa de evasão preocupante. De acordo com dados da ABED de 2018, ainda que a taxa de evasão indique diminuição quando comparada aos anos anteriores, a porcentagem de evasão é uma pauta que abre campo para a reflexão e para a tomada de iniciativas visando atenuá-la, uma vez que o quadro atual é uma grande preocupação para o mercado do ensino a distância. Contudo, o Censo de 2018 faz apontamentos sobre as instituições que detêm conhecimento acerca dos motivos que levam à evasão, salientando o grande número de ofertas em detrimento da dificuldade de acompanhamento dos alunos em alta demanda (ABED 2018, p. 65). 
Desse modo, mesmo havendo a constatação da problemática, são necessárias, também, ações que busquem reduzir os índices representados graficamente acerca da evasão. Tal engajamento necessita ser permanente para que se alcance o real papel da educação, garantindo o acesso, a permanência e a qualidade.

Em análise acerca dos números expostos no censo de 2018 da ABED, apresentados no Gráfico 2, a seguir, os indicadores expressam que houve um aumento na incidência de instituições com baixas taxas de evasão. Os índices nas faixas entre $0 \%$ e 5\% e nas faixas entre $6 \%$ e $10 \%$ passaram de $5 \%$, em 2017 , para $7,4 \%$ e $11,1 \%$, respectivamente, em 2018 . Contudo, a maior porcentagem de instituições $(22,2 \%)$ encontra-se nas taxas de evasão entre $26 \%$ e 50\%. Segundo dados da ABED, em 2017, esse número era de $6 \%$.

Gráfico 2 - Taxa de evasão: percentual dos cursos regulamentados totalmente a distância, semipresenciais e presenciais em 2018

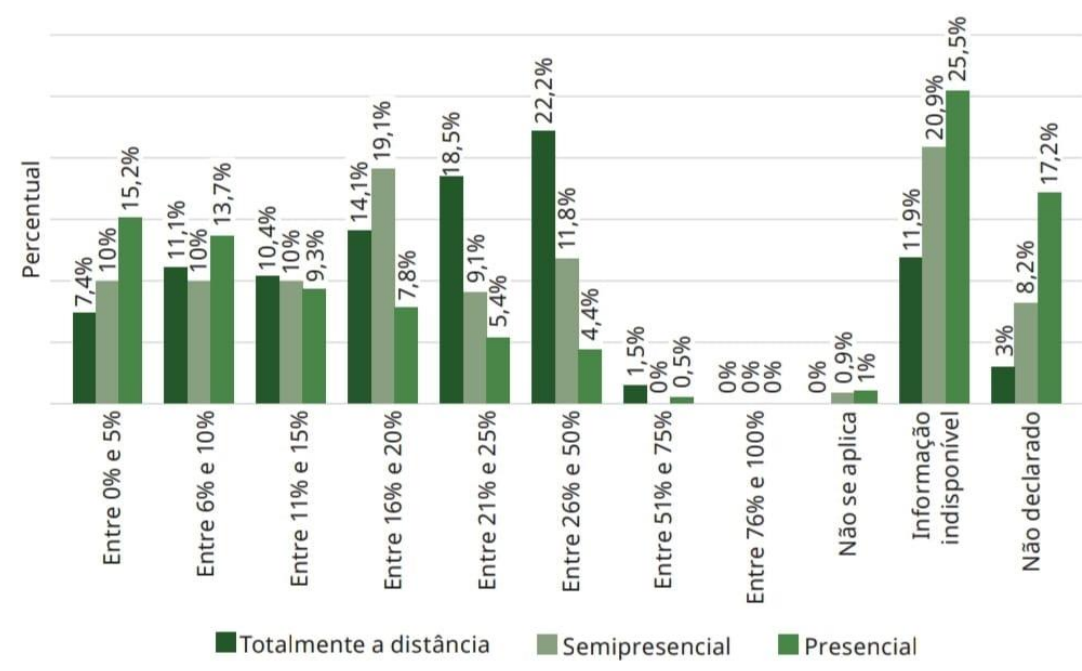

Fonte: Censo ABED (2018, p.65).

É importante diferenciar a porcentagem de conhecimento acerca da evasão e a taxa de evasão propriamente dita. $\mathrm{O}$ fato de as instituições terem conhecimento da causa do problema não significa que essas apresentem um índice considerável de êxito no sentido de abrandar a evasão nos cursos EaD.

Após um panorama geral, observa-se índices ainda negativos quanto à evasão em cursos livres, sejam corporativos ou não corporativos. Há diferença de porcentagem entre as modalidades, mas é importante focar nas taxas de evasão, que são expressivas em ambas, e que justificam a necessidade de recorrer às propostas que combatam de fato a realidade evidenciada pelos indicadores, principalmente em se tratando de cursos livres, que têm, em alguns modelos o chamado Massive Open On-line Course (MOOC), com a não obrigatoriedade de tutoria, algo que potencializa a justificativa na leitura do texto da ABED, quando é diagnosticado que a grande oferta de cursos/vagas implica na dificuldade das instituições em acompanhar o desenvolvimento dos estudantes.

No contexto tecnológico, este advento se faz presente com a informática na educação e, segundo Roebuck (2012), tem no ambiente Virtual de Ensino e Aprendizagem (AVEA) um sistema informatizado que contempla educandos e educadores ao disponibilizar um conjunto de ferramentas on-line que possibilita a oferta de conteúdos assim como a possibilidade de 
solicitar e avaliar atividades submetidas, tudo isso por meio da comunicação direta com os alunos.

Segundo Pereira (et al, 2017), essa dinâmica que visa a obtenção do conhecimento é adquirida na interação entre o aluno e demais atores envolvidos nessa experiência, como colegas e tutores. Todavia, é necessário considerar algo que ainda não é prática constante nos atuais segmentos na oferta de ensino: colocar o aluno no centro das práticas educativas.

Na dinâmica da $\mathrm{EaD}$, o aluno conduz seus estudos à medida que escolhe o momento de iniciá-los, o tempo dedicado a eles e, inclusive, a continuidade, por exemplo. Sendo assim, o estudante tem a possibilidade de controlar e de privilegiar suas ações, de acordo com as prioridades estabelecidas por ele próprio. Desse modo, percebe-se que é a intencionalidade em relação ao curso que recebe o protagonismo desse cenário, e não as questões de envolvimento e interação do aluno no contexto. Dito isto, idealizar um modelo de tutoria automatizada que esteja atenta à grande demanda de alunos em cursos abertos é uma possibilidade de agir e modificar tal cenário.

Ao se apropriar da personalização, os interesses, os limites e as dificuldades dos alunos possibilitam mudanças consideráveis. Sendo assim, na medida em que se eleva a intervenção do estudo e da pesquisa em prol da educação que, no olhar da referida pesquisa, tende a considerar não só o ensino ofertado, mas, essencialmente, o aluno.

De encontro a esse cenário, o Sistema de Notificação Inteligente (SINTA) sustenta uma metodologia embasada, principalmente nas questões mais subjetivas do aluno, a partir de sua interação junto ao formato do curso, expressada por meio de frases, ditas personalizadas, mas que são resultado do delineamento do perfil do aluno, colocando a importância da linguagem e afetividade como influenciadoras determinantes no processo de ensino e aprendizagem, inclusive na modalidade EaD.

O diferencial dessa proposta mostra-se ao focar nos pontos subjetivos dos estudantes, na medida em que suas peculiaridades são refletidas na linguagem (frases) utilizada, o que possibilita uma experiência de interação mais afetiva e menos mecânica, mais personalizada e menos genérica.

Tal proposta é conduzida na perspectiva teórico-educacional construtivista e contempla teóricos, como Vygotsky e Wallon, embasando as perspectivas da aprendizagem e afetividade no ensino. Considera, ainda, a perspectiva de Knowles, em sua teoria da Andragogia, que trata do fazer educação para o público adulto (público para o qual está voltada a pesquisa feita no presente trabalho). Em suma, o modelo de tutoria considera em seu desenvolvimento a personalização do ensino, assim como a importância do perfil do estudante, guiando as principais ações para o ensino que, neste caso, foca-se na $\mathrm{EaD}$.

\section{Marco Conceitual}

$\mathrm{Na}$ Educação a Distância (EaD), o processo de ensino-aprendizagem pode ocorrer de diversas formas. Em virtude de suas potencialidades, é possível dar inúmeras definições para a modalidade, tornando, assim, sua definição um tanto complexa.

Para Belloni (2003), a definição de educação a distância não é análoga à educação presencial, uma vez que a separação física entre aluno e professor durante os processos de ensino-aprendizagem é a principal característica da EaD. Considerando as ponderações do autor é possível observar que é nesse espaço, o qual separa aluno e professor, onde ocorrem as principais maneiras de interação na EaD. 
As características da EaD incluem flexibilização, autonomia e autocontrole. Sobre isto, Litwin (2001) reforça que tais características são possibilidades oferecidas pela modalidade, que não segue um modelo rígido. No entanto, é necessário regular essas possibilidades com recursos pedagógicos a fim de facilitar a construção da aprendizagem. Portanto, identifica-se aqui, a necessidade de criar estratégias para otimizar a apreensão do aluno em cursos oferecidos dentro da modalidade EaD.

Nesse contexto, há uso dos ambientes virtuais de ensino e aprendizagem (AVEAs) para orientar o aluno e interagir com ele. Em mitigada definição, os AVEAs podem ser denominados como websites - local que propicia ao professor o lançamento de materiais didáticos aos alunos de um respectivo curso. Um dos modelos de AVEA é o Modular ObjectOriented Dynamic Learning Environment (Moodle), uma ferramenta de apoio a alunos e professores. A plataforma consiste em um software livre, ou seja, um sistema de código aberto para gerenciamento de cursos. Ele apresenta compatibilidade com variados bancos de dados, e assim possibilita a extensão de plugins.

O Moodle, traduzido como Ambiente de Aprendizado Dinâmico Modular Orientado a Objeto, apresenta possibilidades vantajosas à modalidade $\mathrm{EaD}$, pois é um sistema reconhecido e recorrido em âmbito global para o desenvolvimento de práticas educativas, com recursos tecnológicos, para variados níveis educacionais. Em muitas literaturas da área, sua facilidade de utilização é naturalmente determinada por ser um software livre, favorecendo constantemente a possibilidade de melhorias, implementando ferramentas que coincidam com as demandas conforme o sistema vai sendo utilizado.

Nesse contexto, trata-se de um conjunto de ações para personagens, interagindo com o mesmo propósito tendo como foco o êxito na aprendizagem. Uma dessas interações ocorre nesse exemplo de AVEAs e está relacionada, essencialmente, ao papel da tutoria. É por meio desta que o aluno amplia seu contato com o conteúdo do curso a partir de variadas maneiras de interação que a Educação a Distância oferece.

Ao falar em tutoria, é importante salientar o hercúleo papel do professor, aquele que tem como principal atuação interligar o aluno ao conhecimento e vice-versa. Com as constantes transformações e mudanças de paradigmas que a educação tem vivenciado, o professor, cada vez mais, deixa de ser aquele que detém o conhecimento para assumir o papel de mediador.

Nessa perspectiva, torna-se possível que modelos de tutoria inteligente possam atuar junto aos cursos no Moodle, apoiando os alunos de acordo com as predefinições de cada modelo proposto, considerando determinada problemática ou melhoria percebida. É o caso da proposta do objeto de pesquisa deste trabalho.

\section{Cursos abertos e tutoria automatizada}

$\mathrm{Na}$ modalidade de ensino $\mathrm{EaD}$, existem ramificações de cursos abertos que apresentam similaridades, como autonomia e flexibilidade, mas também algumas diferenças. Dois deles serão considerados: Massive Open Online Courses (MOOCs) e Nano Open Online Course (NOOCs). Sobre MOOC, Inuzuka E Duarte (2012) afirmam que este faz parte de um grupo denominado educação aberta (Open Education), uma proposta que apresenta o ensino de uma maneira mais livre e acessível.

Sobre sua definição, Gené et al. (2014) coloca que o MOOC se trata de um curso voltado à $W e b$, possui um registro aberto e os conteúdos envolvidos em sua proposta tendem a ser compartilhados, tornando-os públicos. Discorrendo sobre suas características, Motta e 
Inamorato (2012) definem MOOC como "letramento digital" o domínio que o aluno precisa ter, minimamente, para usufruir dos conteúdos oferecidos.

O detalhe citado tem muita importância, uma vez que, sem acesso à internet ou às suas linguagens de utilização, o aluno pode ser privado do acesso a essa modalidade de ensino. Disso decorre a dissociação mencionada anteriormente: para o sistema na $\mathrm{EaD}$, são necessários a tecnologia e os profissionais que dinamizam as práticas de ensino.

Apesar das diferentes definições sobre cursos abertos, Inamorato (2009) enfatiza que o modelo de curso rompe barreiras para o acesso ao ensino. Questões voltadas à possibilidade física, social, de aprendizagem e temporais são contornadas diante das possibilidades que os cursos abertos oferecem. A flexibilização é outro ponto positivo, uma vez que os conhecimentos prévios e a estrutura modular dos cursos são características principais.

Os cursos abertos apresentam, em seu cerne, características e possibilidades que favorecem o acesso à educação. $\mathrm{Na} \mathrm{EaD}$, as propostas estão sempre interligadas a essa perspectiva e consolidam a modalidade como uma incentivadora à educação e de grande potencial inovador para as práticas educativas. Por sua característica de ser curso livre e sem tutoria, os cursos abertos oferecem uma gama de oportunidades no que diz respeito à acessibilidade e diferentes ramificações de interesses e temas. Considerando a facilidade de acesso e a característica de ser o próprio aluno a conduzir sua aprendizagem, faz-se aí, o gatilho para a evasão, ou seja, a não conclusão, elevando as taxas negativas relacionadas a esse tipo de curso.

A tutoria, em seu formato habitual, tende a acompanhar o ritmo dos alunos. Todavia, seria complexo acompanhar uma demanda tão grande como é possibilitado em cursos MOOC. É sugerindo, portanto, um formato de tutoria inteligente que se atente às necessidades pedagógicas dos estudantes e que considere outras questões que atenuem as possibilidades de evasão.

Para tanto, se faz necessário considerar as perspectivas dos profissionais que atuam na $\mathrm{EaD}$, essencialmente em cursos MOOC, na intenção de otimizar um modelo de tutoria inteligente - automatizada - que fortaleça o papel de atuação de tutoria considerando as necessidades pedagógicas dos estudantes.

\section{Aprendizagem e afetividade no cenário $\mathrm{EaD}$}

A Educação a Distância possui características específicas no que diz respeito ao seu formato e, também, no processo de ensino-aprendizagem dentro de sua metodologia. Segundo Pierre Lévy (1998), nas formas de relação social, algo que reflete e é refletido na escola, o contato com essa nova "intervenção" metodológica - as tecnologias digitais - propiciam maior proximidade com diferentes pensamentos e o convívio com o pensamento coletivo tende a melhorar a formação do cidadão enquanto ser social.

Posto isso, o desafio parece ser ultrapassar a questão do uso das tecnologias digitais como meras ferramentas metodológicas para ensinar os mesmos conteúdos nas escolas ou simplesmente para capacitar o estudante para o mercado de trabalho. $\mathrm{O}$ aluno precisa ser foco principal das ações voltadas ao ensino, visando promover essencialmente sua aprendizagem.

Sendo assim, é possível agregar tecnologias digitais ao pensamento filosófico, por exemplo, e transformar cidadãos em sujeitos plenamente formados, na medida em que utilizam esse artifício e fazem deste uma maneira consciente de mudanças positivas em si e a partir de si. Posto esse cenário, algumas teorias de aprendizagem significam a forma de ensinar e 
aprender, inclusive na $\mathrm{EaD}$, pois a forma de condução, ou seja, os meios tecnológicos, não significa alteração no processo ou no sujeito (aluno).

Considerando as perspectivas citadas, o referencial teórico cita, propositalmente, pensadores que, mesmo diante de diferentes vertentes metodológicas, culminam inegavelmente na questão da interação afetiva como influenciadora nos processos de aprendizagem. O que talvez pareça redundância de pensamento dito de maneira diferente, sugere, na verdade, a legitimação da importância do conceito de aproximação entre os sujeitos - por meio das múltiplas linguagens de comunicação - para a eficácia dos processos de aquisição do conhecimento e estímulo positivo.

Para abordar essa temática, valemo-nos das reflexões de Vygotsky (1988), quando o autor diferencia a adaptação entre homens e animais. $O$ primeiro considera signos carregados de sentido e estes se modificam, conforme as mudanças do meio. $\mathrm{O}$ segundo segue um condicionamento mecânico, instintivo. $\mathrm{O}$ sujeito, então, vive em constante processo de ressignificação, à medida que interage com o meio e absorve seus novos sentidos. Nesse processo, a interação e a comunicação por meio da linguagem são essenciais.

Levando a perspectiva do autor às interações na $\mathrm{EaD}$, os apontamentos necessários para uma apropriação de significados estão presentes, pois existem os sujeitos envolvidos (alunos, colegas, professores, tutores). Há um dado conhecimento a ser transmitido e há diferentes possibilidades de interação. Nesse mapeamento de ações, evidencia-se que aprender é possível na $\mathrm{EaD}$.

Avançando em teorias no processo de aquisição do conhecimento pelo sujeito, Wallon (1979) ressalta em seus estudos, que o desenvolvimento do sujeito depende do meio para ocorrer. Sendo assim, a maneira e o tipo de interação são essenciais para definir a qualidade desse aprendizado. Tendo em vista o que afirma o autor, nas interações que ocorrem durante a aprendizagem na $\mathrm{EaD}$, não basta que haja ferramentas ou demais adequações se isso não for utilizado com cautela, visto que é na qualidade dessa interação, que posteriormente o autor enfatiza como afetividade, onde ocorrerá trocas significativas que resultarão em aprendizado.

Levando as considerações dos teóricos anteriores ao cenário dos estudantes - dito jovens e adultos - faz-se necessário, ainda, atentar à Metodologia Andragógica que se constitui em conhecimento essencial para compreender melhor o cenário que estamos explorando aqui. Nesse sentido, Knowles (1980 apud OSÓRIO, 2003) define na Andragogia o conjunto de princípios para promover a aprendizagem aos adultos.

Nesse sentido, o professor é agente facilitador, que visa em seu papel: preparar o aluno, proporcionar uma atmosfera que facilite a aprendizagem, planejar, diagnosticar as necessidades do estudante, formular objetivos e intentar um padrão de experiência visando a aprendizagem, conduzir adequadamente tais experiências e avaliar os resultados, objetivando novos diagnósticos dessas necessidades de aprendizagem.

Para Knowles (1970), a Andragogia considera princípios que levam em conta as vivências, os interesses e as expectativas do aprendiz adulto e toda a complexidade imbuídos nesse sujeito, que já exerce autonomia maior.

Dentro dessa concepção teórica, Knowles (2009 apud OSÓRIO, 2003) elenca cinco pressupostos que serviram como fundamentos para a teoria de aprendizagem de adultos:

a) adultos são motivados a aprender, na medida em que experimentam que seus interesses serão satisfatórios;

b) aquilo que guia a aprendizagem do adulto está ligado na vida; 

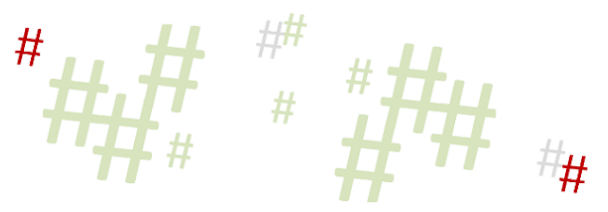

a experiência é fonte essencial para que o adulto aprenda;

c) adultos possuem a necessidade de auto regimento;

de acordo com a idade, crescem as diferenças individuais entre os sujeitos.

Sendo assim, ao reconhecer que há diferentes alunos, a lógica enseja a conclusão de que se trata de diferentes singularidades, uma vez que, com diferentes particularidades, a perspectiva de todas se adequarem a iniciativas educativas reguladoras de ensino genérico e uniforme teria menor probabilidade de êxito.

Corroborando as últimas ponderações, Karolczak (2009) defende que a Andragogia se fundamenta, de maneira fulcral, no construtivismo e no interacionismo, teorias de Piaget e Vygostsky, visto que os aprendizes adultos constroem o seu saber a partir de motivações internas e externas. Isso fortalece a fundamentação teórica que norteia a presente pesquisa, de modo a levar considerações científicas ao modelo de tutoria que é objeto desse trabalho.

É de substancial importância que o docente atuante no campo da EaD tenha conhecimento, acesso e clareza sobre as complexidades existentes no processo de aprendizagem ligadas ao perfil do curso bem como dos alunos com os quais trabalham. Isso exige dele a aplicação de ações que ressignifiquem os fundamentos epistemológicos, adequando-os ao uso da Metodologia Andragógica.

\section{Desenvolvimento metodológico}

Esta pesquisa sistematizou um modelo de notificação inteligente e deparou-se com a questão de como alcançar essa sistematização a partir da interação do aluno com o curso. $\mathrm{Na}$ intenção de realizar as etapas de maneira mais eficaz possível, foi determinada uma metodologia que considerasse todos os interesses envolvidos: dificuldade em acompanhar grande demanda de alunos, processos que facilitam a atuação de tutoria na interação com os estudantes, sistematização de um procedimento eficaz que corresponda ao problema observado, que é a taxa de evasão de alunos em cursos livres.

Para este trabalho, optou-se pela pesquisa exploratória, uma vez que é necessária a união de algumas etapas que a caracterizam, segundo Gil (2002): o levantamento bibliográfico acerca da temática, entrevistas com personagens que têm experiência concreta com o problema pesquisado, assim como a análise de alguns exemplos com o intuito de estimular a compreensão. Esse percurso foi trilhado mediante a consideração de trabalhos correlatos, levantamento bibliográfico sobre modelos de tutoria e espaço para a fala de profissionais que atuam na $\mathrm{EaD}$ na etapa de entrevista.

\footnotetext{
Estas pesquisas têm como objetivo proporcionar maior familiaridade com o problema, com vistas a torná-lo mais explícito ou a constituir hipóteses. Pode-se dizer que estas pesquisas têm como objetivo principal o aprimoramento de idéias ou a descoberta de intuições. Seu planejamento é, portanto, bastante flexível, de modo que possibilite a consideração dos mais variados aspectos relativos ao fato estudado. Na maioria dos casos, essas pesquisas envolvem: (a) levantamento bibliográfico; (b) entrevistas com pessoas que tiveram experiências práticas com o problema pesquisado; e (c) análise de exemplos que "estimulem a compreensão" (SELLTIZ et al 1967, p.63).
}

Considerar a abordagem descrita, portanto, foi essencial, uma vez que se fez necessária uma imersão no universo da $\mathrm{EaD}$ a partir do ponto de vista dos personagens que nele estão inseridos. Trata-se do recorte de uma "comunidade" de modelo educacional com suas peculiaridades e complexidades que necessitavam ser exploradas e observadas para alcançar maior compreensão sobre o problema que norteia a pesquisa, a evasão. 
Os sujeitos inicialmente considerados foram os profissionais que atuam em cursos EaD do Instituto Federal de Educação, Ciência e Tecnologia do Rio Grande do Sul (IFRS) e, mais adiante, surgiram os estudantes com os quais foram testadas as frases personalizadas que resultaram na sistematização da tutoria SINTA. Sendo assim, o grupo focal expandiu-se no decorrer do trabalho e recebeu olhares diferenciados, de acordo com a necessidade apresentada a cada etapa da pesquisa.

A pesquisa considerou o cenário de cursos ofertados pelo IFRS para analisar a necessidade de maiores intervenções práticas nos cursos abertos. Para isso, realizou-se uma etapa concomitante, voltada a dados mais exatos sobre a instituição, e outra que focou em entrevista de campo com professores e outros profissionais que atuam nos cursos da mesma instituição.

Um convite via $e$-mail foi encaminhado aos participantes, propondo um encontro batizado de "conversa aberta sobre EaD". Esse encontro reflexivo ocorreu em 26 de abril de 2018, com duração de duas horas e possibilitou muitos apontamentos importantes no que se refere aos cursos abertos oferecidos pela instituição IFRS.

Essa etapa consistiu em ouvir os profissionais citados, com o intuito de identificar a linha de intersecção entre o ponto de vista advindo da prática na $\mathrm{EaD}$ e a hipótese inicial da problemática sobre as razões que levam à evasão dos estudantes nos cursos livres. Esse processo apoiou-se no segmento metodológico que considera a entrevista como instrumento de investigação social e fonte possível de obtenção de dados.

Durante o diálogo, os participantes enfatizaram sua perspectiva enquanto profissionais e também, enquanto participantes de cursos na educação a distância, algo que foi além do esperado e apresentou-se, de início, como ponto-chave para a sistematização do assistente inteligente: considerar os sujeitos, inclusive para elaborar a sistematização que, posteriormente, irá interagir com ele.

Como tratava-se de uma entrevista não convencional, o diálogo foi iniciado com o tema "evasão", podendo ser abordado a partir de qualquer perspectiva. Dessa maneira, muitos relatos foram pronunciados, assim como experiências que fogem ao convencional (tal como receber, por parte de um aluno, uma cobrança de retorno para uma pergunta específica feita no link do curso MOOC e, por não haver possibilidade de retorno no próprio curso, tendo sido cobrado presencialmente do professor/tutor).

Conforme o diálogo se estendia, foi possível identificar os principais pontos de vista, hipóteses e inquietudes acerca da temática proposta e, embora não houvesse questionário formal para que cada participante pudesse preencher com respostas, houve muitos momentos de encontro de reflexões semelhantes e engajamento para possíveis soluções diante do problema que iniciou o diálogo.

A análise da fala dos entrevistados resultou, portanto, em variadas categorizações, e a próxima a ser demonstrada diz respeito às principais situações recorrentes nos cursos declaradas pelos entrevistados. Com base em suas falas, nas reflexões em conjunto e no consenso foi elaborado o Quadro 1, a seguir: 
Quadro 1 - Justificativa e Proposição

\begin{tabular}{|l|l|}
\hline \multicolumn{1}{|c|}{ JUSTIFICATIVA } & \multicolumn{1}{c|}{ PROPOSIÇÃO } \\
\hline $\begin{array}{l}\text { Os alunos esquecem do curso em virtude de outros } \\
\text { compromissos e, tratando-se de uma modalidade de } \\
\text { ensino que exige disciplina e por não haver tutoria } \\
\text { permanente, isso se agrava além das inúmeras razões } \\
\text { que os levam a fazer o curso e que nem sempre estão } \\
\text { ligadas a interesses subjetivos, pessoais que acabam } \\
\text { colocando em dúvida a real necessidade de se dedicar } \\
\text { ao curso }\end{array}$ & $\begin{array}{l}\text { Lembrar ao aluno sobre o curso permanentemente e } \\
\text { não somente quando há indícios de possível evasão, } \\
\text { de maneira a mantê-lo no foco inicial; }\end{array}$ \\
\hline $\begin{array}{l}\text { Formato genérico do curso não favorece os } \\
\text { diferentes perfis de alunos que acabam se sentido } \\
\text { "largados" nesse processo e favorece o } \\
\text { distanciamento do curso; }\end{array}$ & $\begin{array}{l}\text { Desempenhar mecanismos para: reconhecer e } \\
\text { favorecer o perfil do aluno; fortalecer seu interesse } \\
\text { no curso; detectar as dificuldades e, de maneira mais } \\
\text { real possível, estabelecer uma comunicação através } \\
\text { de interação subjetiva, ou seja, considerando as } \\
\text { características de cada aluno. }\end{array}$ \\
\hline
\end{tabular}

Fonte: Elaborado pelos autores (2021).

De acordo com o referido no quadro acima, as razões mais citadas na fala dos profissionais da $\mathrm{EaD}$ entrevistados foram:

a) esquecimento do curso, por razões externas que se fazem mais importantes em detrimento dos motivos que o aluno possui em relação ao curso;

b) alguns formatos de cursos são estáticos e não apresentam elementos que possibilitem uma adequação ao perfil do aluno, algo que gera, em alguns, a sensação de "abandono" e favorece o afastamento em relação ao curso.

Após a leitura das contribuições obtidas, a partir dos relatos dos profissionais participantes do grupo focal, foi delineada uma metodologia para a criação do Sistema de Notificações Inteligentes. Conforme imagem que segue (Figura 1), a metodologia considera as etapas dos estudantes em relação ao curso, a partir de sua interação com ele: nota, acesso e visualização dos materiais. A partir desses dados foram lançadas frases automatizadas para os estudantes, correspondendo o estilo da frase (personalização ) ao estudante que se encontra no quadro de desempenho correspondente aos dizeres da frase.

Valendo-se dessa explicação, o modelo de tutoria, ou seja, a metodologia SINTA constitui-se enquanto produto deste trabalho científico e a Figura 1, a seguir, explicita suas principais características de desenvolvimento, marcando como diferencial dessa proposta, a possibilidade de personalizar a atuação de tutoria a partir da contribuição dos próprios estudantes, se diferenciando das demais proposta existentes desse segmento.

O diferencial do projeto consiste na personalização: o aluno terá a opção de não receber as frases, bastando escolher essa opção na interface. Essa etapa é também essencial, pois, a aceitação ou não dessa vai referenciar em absoluto se a proposta de tutoria automatizada contempla as necessidades desse estilo de curso, além de indicar se a proposta será bem-aceita ou não pelos adeptos da modalidade. 
Figura 1 - Esquema de periodicidade

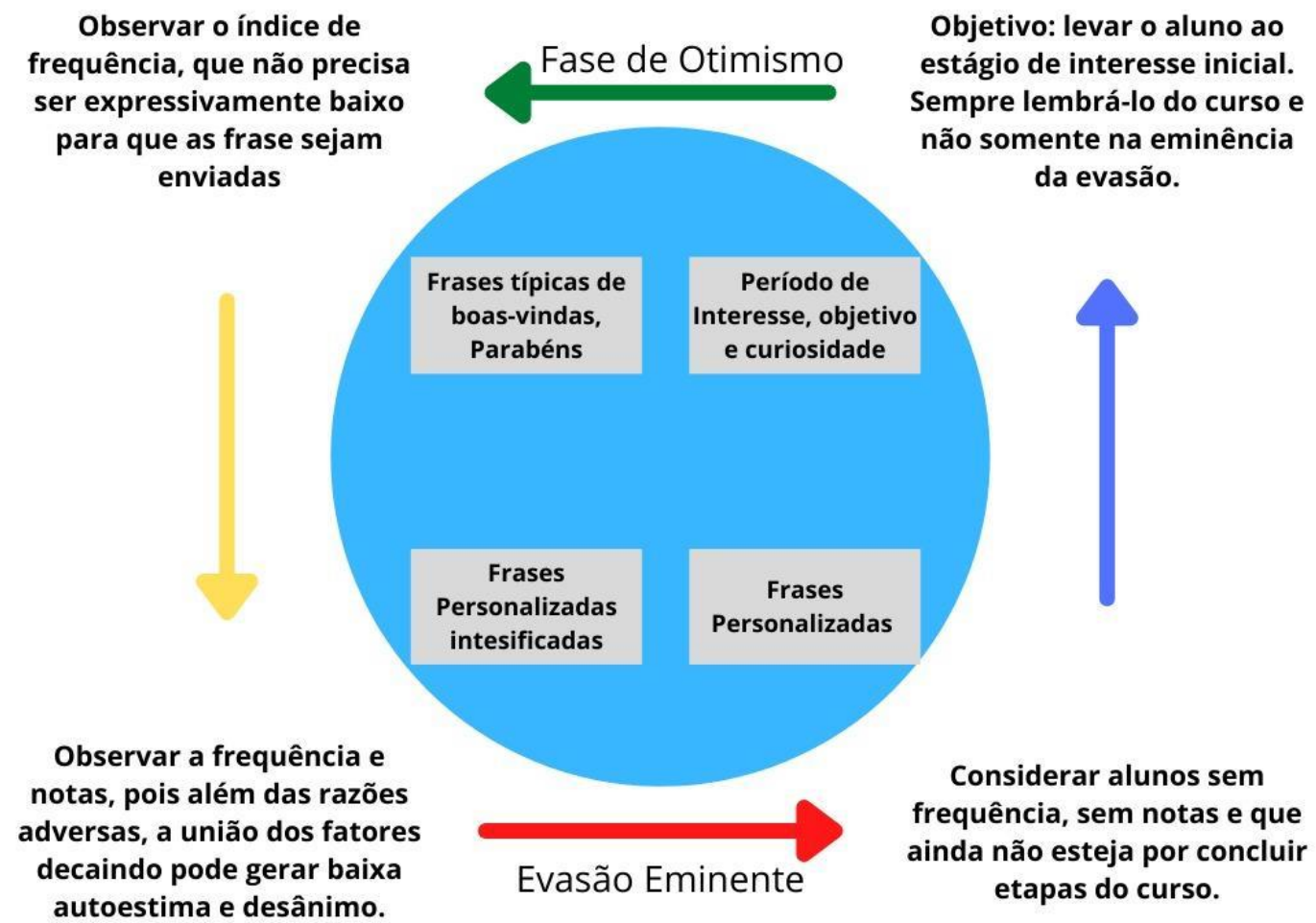

Fonte: Elaborado pelos autores (2021).

A partir desse esquema, uma árvore de decisão foi elaborada para a criação das frases automatizadas personalizadas, cruzando as informações do estudante (preferência de tratamento, emoji de identificação, linguagem preferida) com as informações em relação ao curso (acesso, nota e interação com materiais).

A árvore de decisão possibilitou uma personalização mais eficaz para as frases automáticas, o que determinou a metodologia para o modelo de tutoria. A árvore de decisão consiste em cruzar informações sobre o aluno no curso com aquelas que dizem respeito às suas informações de predileções (escolhas, propensão, inclinação).

Segundo os estudos de Zuben e Attux (2008), o processo que define as árvores de decisão é fundamentado na estratégia de bottom-up, na abordagem do pensamento. O ensino considera projetos, passo a passo e por decomposição, a fim de compreender a fragmentação das informações colhidas e uma visão mais detalhada de fatos que se pretende absorver. Para os pesquisadores, algumas aplicações do sistema seguem as condições:

Toda informação sobre cada objeto (caso) a ser classificado deve poder ser expressa em termos de uma coleção fixa de propriedades ou atributos. Dessa forma, objetos distintos não podem requerer coleções distintas de atributos. Bases de dados que atendem a este requisito são denominadas flat files.O número de classes pode ser definido a priori, o que transforma a modelagem num processo de treinamento supervisionado, ou então será definido automaticamente a partir dos dados disponíveis, o que caracteriza um processo de treinamento não-supervisionado.

[...] Deve haver uma quantidade bem maior de objetos do que classes, inclusive para permitir a aplicação de testes estatísticos. A quantidade adequada de objetos vai depender do número de atributos, do número de classes e da complexidade intrínseca ao modelo de classificação.A tarefa de classificação deve poder ser implementada 
de forma lógica, ou seja, empregando uma base de regras de decisão. Assim, a classificação de cada objeto pode ser descrita por uma expressão lógica. Em contrapartida a este requisito, podemos mencionar a classificação por operações aritméticas, empregada em discriminantes lineares, por exemplo, que realizam a classificação por uma combinação linear dos atributos, seguida da comparação com um limiar. (ZUBEN e ATTUX, 2008, p.5)

Considerando as definições dos autores, este estudo apoiou-se na perspectiva de dados consolidados por propriedade e características, cada um sendo associado a uma classe, dentro de aplicabilidades possíveis. Ainda, os atributos devem ter a perspectiva de variáveis observáveis e independentes, que vão assumindo novos valores, de acordo com o cruzamento de informações com outros domínios, como nos mostra o Quadro 2 a seguir:

Quadro 2 - Proposição: coleta de dados unificados

\begin{tabular}{|c|c|}
\hline \multicolumn{2}{|c|}{ Escolha uma imagem com a qual você se identifique } \\
\hline A. & Distraído 엉: Natural, despojado, informal; \\
\hline B. & 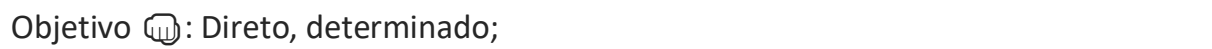 \\
\hline C. & Emocional [e- : Emotivo, afetivo, sensível \\
\hline \multicolumn{2}{|c|}{ Indique qual é o seu objetivo no curso } \\
\hline D. & Conhecimento \\
\hline E. & Certificado / Trabalho \\
\hline F. & Formação \\
\hline \multicolumn{2}{|c|}{ Selecione qual frase combina com você: } \\
\hline G. & E aí! Bom te ver no curso! \\
\hline H. & Prezado, boa tarde! É um prazer tê-lo em nosso curso. \\
\hline I. & Olá! É ótimo ter você no curso! Juntos é bem melhor e faremos um trabalho incrível! \\
\hline
\end{tabular}

Fonte: Elaborado pelos autores (2021).

Essa etapa é importante para designar o cruzamento das informações e resultar nas variações de frases possíveis. Juntamente com dados descritos no quadro seguinte, as informações tendem à criação, personalização e disparos automáticos de frases. Para esse sistema ser efetivado, será utilizado a ação de um plugin que fará parte da utilização sistêmica do Moodle. Um processo possível, simples e perfeitamente aplicável nesse modelo de plataforma.

Como parte finalizadora desse processo de cruzamento de dados, observa-se o quanto é importante atentar aos dados dos estudantes e a observação de seu desempenho em relação ao curso, pois disso depende a eficácia do cruzamento de dados e formação coerente das frases. Essa elaboração consistiu na segunda fase da elaboração da árvore de decisão, ou seja, é desse resultado que surgem as frases e o principal diferencial da proposta elaborada na metodologia SINTA, a personalização, conforme evidenciado no Quadro 3, a seguir:

Quadro 3 - Indício de evasão

\begin{tabular}{|c|c|}
\hline Situação & Mensagem \\
\hline $\begin{array}{c}\text { Se A-, B + de 21 dias, } \\
\text { C 0\% }\end{array}$ & $\begin{array}{c}\text { Quanto tempo, João! Sentimos sua falta por aqui. } \odot \text { Já conferiu o material que } \\
\text { preparamos para você? Não desista }\end{array}$ \\
\hline $\begin{array}{c}\text { Se A-, B +de 21 dias, } \\
\text { C 50\% }\end{array}$ & $\begin{array}{r}\text { Oi, João! Você já viu metade do material, parabéns! Agora corre lá no curso para } \\
\text { aplicar o que você já viu. Você consegue! }\end{array}$ \\
\hline $\begin{array}{c}\text { Se A-, B +de 21 dias, } \\
\text { C acima de 70\% }\end{array}$ & João, gostou do conteúdo? Sentimos sua falta. Acesse o curso e garanta seu \\
certificado. Não perca essa chance!
\end{tabular}

Fonte: Elaborado pelos autores (2021). 
Sendo A - o perfil do estudante; B - seu rendimento em relação ao curso e C a periodicidade de acesso ao curso, o resultado da frase possível serão os exemplos acima, hipoteticamente. Dessa maneira o estudante será abordado em diferentes etapas de seu curso, correspondendo ao seu estágio de desempenho e, dessa forma, o aluno se sentirá acompanhado e estimulado a concluir seu curso, alcançando assim o objetivo principal da proposta de tutoria automatizada. Todo esse processo atenderá uma grande demanda de estudantes, auxiliando em trabalhos de tutoria de maneira automatizada e privilegiando o processo de aprendizagem e as necessidades pedagógicas dos estudantes.

\section{Aplicação e resultados}

A proposta de Tutoria Automatizada SINTA, com sua metodologia devidamente delineada, foi testada junto aos cursos do IFRS. Conforme disponibilidade, a aplicação ocorreu entre os meses de agosto e setembro de 2020, no curso "Windows Server: Instalação e administração". Trata-se de um dos cursos oferecidos pelo IFRS em formato aberto, ou seja, segue a metodologia que não contempla tutoria e possibilita ao estudante conduzir seus estudos.

O curso de 7 módulos tem carga horária de 60 horas e permite a obtenção do certificado após a conclusão, a contar 8 dias a partir da inscrição. Ele é voltado para interessados na área de informática e para aqueles com interesses afins. Foi neste cenário no qual aconteceu a entrevista com professores e funcionários envolvidos com os cursos semelhantes ao "Windows Server: Instalação e administração". Ao todo, foram considerados 20 estudantes. Destes, 4 estavam há mais de 72 dias sem acessar o curso e sem obtenção de notas; outros 6 alunos visualizaram o conteúdo do curso (sem qualquer interação) e sem notas; enquanto 10 estudantes estavam com último acesso inferior a 20 dias (para mais ou para menos) e com alguma obtenção de nota.

Os perfis acima foram escolhidos aleatoriamente, mas sempre considerando possíveis perfis cabíveis à metodologia, caso contrário, a aplicação do SINTA não poderia oferecer resultados plausíveis. No entanto, a aplicação precisou submeter-se à realidade do andamento do curso em questão, ou seja, acompanhar alunos já ingressantes e que já tinham perfis bem marcantes e sem intervenção de tutoria alguma.

No período de um mês, todos os estudantes receberam um e-mail, alternativa que simula a interação das frases, considerando o estágio de cada estudante. Ainda de acordo com a etapa do aluno, os e-mails seguiram uma periodicidade, conforme a metodologia prédetermina. Por exemplo: a cada dois dias, para alunos com a menor taxa de assiduidade, enquanto, para aqueles com a assiduidade maior, foram encaminhados $e$-mails com lapso superior de tempo.

O produto SINTA foi aplicado em um curso aberto, sem tutoria, na instituição IFRS, porém, em andamento. Diante de tal circunstância, o "Sistema Inteligente Tutor-aluno" foi aplicado dentro das possibilidades apresentadas e utilizou o máximo de suas etapas metodológicas para alcançar resultados expressivos para análise. Segue, abaixo, na Figura 3, exemplo de $e$-mail enviado. 
Figura 3 - e-mail: simulação de interação SINTA

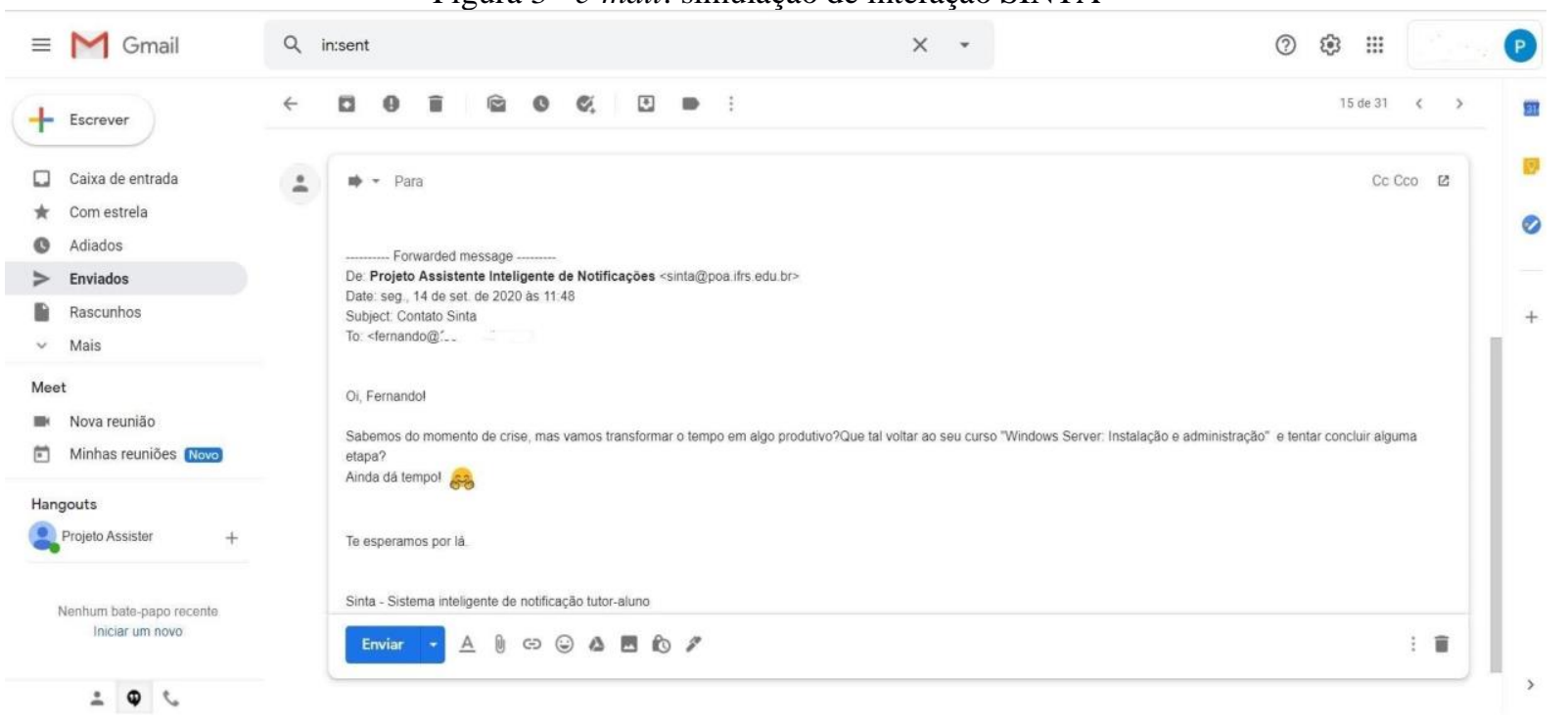

Fonte: gmail.google.com

O formato do e-mail não comportava resposta/retorno por parte dos estudantes, sendo a comunicação com o curso a única possibilidade de observar se eles foram motivados a retomar seus estudos. Dos 20 alunos acompanhados, aqueles com menos assiduidade, que não acessaram o curso, o conteúdo e sem obtenção de notas mantiveram o perfil, mesmo com as variadas mensagens e a proposta enfática de periodicidade de emissão.

Por outro lado, no tocante aos 10 estudantes mais ativos junto ao curso (com algum percentual de frequência, vista de material e nota), 4 demonstraram correspondência, se considerarmos as datas de envio das mensagens por e-mail e a data de retorno dos alunos ao curso. Essa observação já demonstra indícios positivos quanto aos resultados da aplicação do SINTA e apresentou interações e periodicidade desta de variadas maneiras, conforme alternava-se o aluno para o qual se encaminhou as frases.

Como salientado anteriormente, os estudantes acompanhados na pesquisa não foram contatados desde seu ingresso no curso. Isto significa que a etapa de delineamento de perfil inicial não pôde ser realizada. Sendo assim, foram seguidas as demais categorias determinadas na metodologia e inferidos estilos de frases que se aproximam do perfil do estudante, de acordo com o desempenho no curso, por exemplo.

Observando a Figura 3, acima, o aluno F, cuja interação junto ao curso determinou o estilo de frase inserida no e-mail foi considerado para seu perfil o índice de acesso ao curso (conforme é possível constatar, de 5 de junho a 4 de setembro - 1 acesso) e, posteriormente, verificado se o aluno retomou o curso, quanto tempo isso demorou e qual foi sua interação (atividades, leitura de material) em relação ao curso.

Tal metodologia foi utilizada de forma semelhante para todos os alunos contatados, modificando apenas o estilo na composição das mensagens. Posteriormente foi observada a periodicidade de retomada de ação do aluno em relação ao curso. Conforme conclusão gerada e exemplificada na Figura 4, a seguir, há uma intensa atuação no curso após poucos dias da emissão das frases, mais precisamente na data em que o aluno recebe a mensagem por $e$-mail (notificação SINTA). 
Figura 4 - Acesso do aluno ao curso

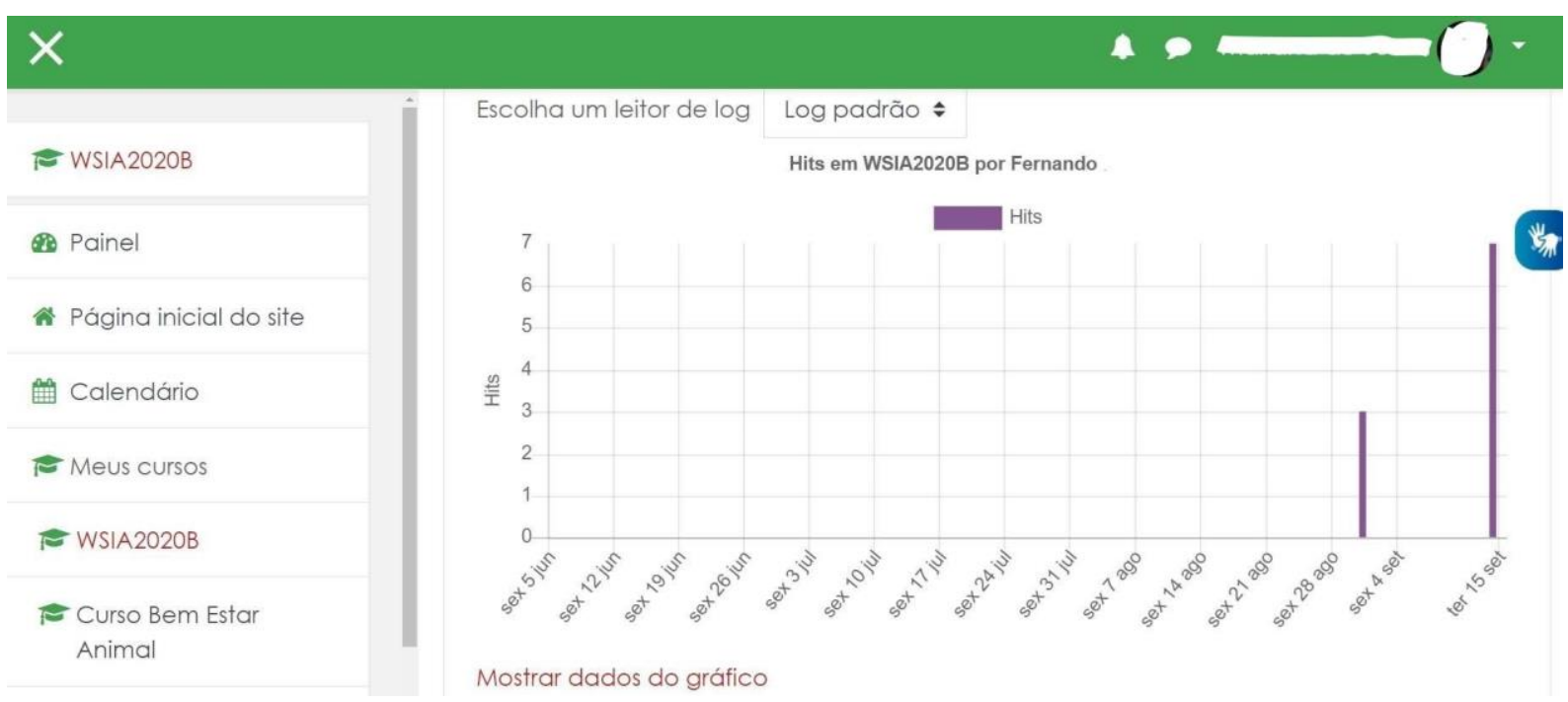

Fonte: Elaborado pelos autores (2020).

A mensagem foi enviada em 14 de setembro de 2020 e após um dia foi possível constatar a interação do estudante em relação ao curso - no dia 15 de setembro - demonstrando, ainda, o dobro de interação que ele havia tido em seu último acesso. Embora tenha havido interação anterior por parte do estudante - uma possibilidade também contemplada na metodologia SINTA - após a intervenção com as "frases automatizadas", o retorno deste estudante foi quase imediato e impulsionou uma maior interação junto ao curso.

Embora o produto SINTA, enquanto proposta concreta que impulsionou a presente pesquisa, tenha sido aplicado em formato parcial, o resultado, no mínimo, demonstrou que há potencial de êxito no propósito para o qual a tutoria foi idealizada. Os resultados demonstram que, embora o modelo de frases tenha sido inferido, houve assertividade e obteve resultados positivos na aceitação daqueles que as receberam, conforme nos mostra a Figura 5 a seguir:

Figura 5 - Dados de Análise

\begin{tabular}{cccc}
\hline Aluno & Nota & Frequência & Interação \\
A -4 & 0 & +72 dias & - \\
B -6 & 0 & +50 dias & Visualização \\
C -10 & com nota & $+/-20$ dias & Variadas interações \\
\hline
\end{tabular}

Após aplicação do produto SINTA - interação por e-mail

\begin{tabular}{ccc} 
Aluno & Reação & Resultado \\
A & 0 & - \\
B & 0 & - \\
C & 4 de 10 & conclusão, visualização e questionários \\
\hline
\end{tabular}

Conforme a referida Figura 5, após a aplicação do produto SINTA, 40\% dos alunos corresponderam à proposta (considerando a variável dentre os 10 alunos que interagiram dentro do curso) e $60 \%$ mantiveram-se com o perfil inalterado (novamente considerando variáveis, por se tratar de alunos que não tiveram acompanhamento precoce perante o curso, pois encontravam-se em perfis já definidos). 
Vale lembrar que os resultados obtidos nesta pesquisa são resultados preliminares e que apontam para necessidade de testes mais amplos, uma vez que a proposta SINTA é a prototipação de uma metodologia teórica, baseada em conceitos pedagógicos, essencialmente, e exige maior desenvolvimento técnico para sua eficácia. Uma proposta dessa amplitude permite ser aplicada em diferentes AVEAs e, portanto, todo o trabalho aqui demonstrado se fortalece como possibilidade provável de melhorias para o sistema $\mathrm{EaD}$ a partir do modelo de auxílio à tutoria idealizada.

Logo, se considerarmos esse percentual para uma escala maior, com todos os recursos previsto na metodologia desenvolvida, há, no mínimo, $20 \%$ de retorno positivo nos cursos abertos (observando a quantificação geral do grupo). Essa possibilidade, dentro de uma realidade que é assombrada com altos índices de evasão, significa caminhar para uma mudança real e positiva, onde todos os envolvidos tendem a ganhar em forma de educação, qualidade e ressignificação de trabalho.

As possibilidades apontadas no decorrer da pesquisa, mas que não foram contempladas na metodologia, indicam a abertura de um campo para maior autonomia dos tutores, com acesso a comandos que possam criar ou modificar as frases estipuladas pelo plugin. Porém, deve-se manter a periodicidade inicialmente estipulada na metodologia, pois se trata do alicerce de desenvolvimento da personalização dos alunos dentro do curso.

Com maior engajamento tecnológico, o protótipo considera a perspectiva de inferir possíveis fases/horários de acesso em que o aluno acessa/acessou o curso, para disponibilizar as frases de modo a ampliar a probabilidade de serem lidas, avançando, também, para mensagens em formato de notificação em dispositivo móvel. Isso significa que a proposta do SINTA pode avançar em suas expectativas iniciais e ser usufruída por diferentes cursos e/ou instituições, uma vez que desenvolveu, para além do rendimento do aluno em cursos, uma possibilidade de acesso a esse estudante, a partir de suas predileções.

\section{Referências}

ABED, Associação Brasileira de Educação a Distância. 2016. Censo EaD.br 2016:

Relatório Analítico da aprendizagem a distância no Brasil. Disponível em: CENSO_DIGITAL_EAD_2018_PORTUGUES.pdf. Acesso em 12 dez. 2020.

BELLONI, M. L. Educação a distância. 3. ed. Campinas: Autores Associados, 2003.

GIL, A.C. Como elaborar projetos de pesquisa. 4. ed. São Paulo: Atlas, 2002.

INAMORATO, A. O conceito de abertura em EAD. In: LITTO, Fredric Michael; FORMIGA, Marcos. (Orgs). Educação a distância: o estado da arte. São Paulo: Pearson Education do Brasil, 2009, p. 290-296.

INUZUKA. A. M: DUARTE. T. R. Produção de REA apoiada por MOOC. Recursos educacionais abertos: Práticas colaborativas e Políticas Públicas. Casa da Cultura Digital. São Paulo, 2012.

KAROLCZAK, Maria Eloisa; KAROLCZAK, Marcio Martins. Andragogia - Liderança, Administração e Educação: uma nova teoria. Curitiba: Juruá, 2009.

KNOWLES, M. S. The modern practice of adult education: andragogy versus pedagogy. New York: Association Press, 1970. 
LÉVY, P. A inteligência coletiva: por uma antropologia do ciberespaço. São Paulo: Loyola, 1998.

LITWIN, E. (org). Educação a distância: temas para o debate de uma nova agenda educativa. Porto Alegre: Artmed, 2001.

MOODLE, Moodle. Disponível em: https://moodle.org/course/view.php?id=35. Acesso em 15 dez. de 2020.

OSÓRIO, A. Educação Permanente e Educação de Adultos. Lisboa: Horizontes Pedagógicos, 2003.

PEREIRA, A. S. et al. Metodologia da Aprendizagem em EaD. UAB/NTE/UFSM, Santa Maria (RS), 2017.

ROEBUCK, K. Virtual Learning Environments (VLE): High-impact Strategies- What You Need to Know: Definitions, Adoptions, Impact, Benefits, Maturity, Vendors. Dayboro: Emereo Pub, 2012.

SELLTIZ, Claire et al. Métodos de pesquisa nas relações sociais. São Paulo: Herder, 1967. VYGOTSKY, L.S. A formação social da mente. 2 ed. Martins Fontes: São Paulo, 1988.

WALLON, H. Do acto ao pensamento: ensaio de psicologia comparada. Lisboa, Portugal: Moraes, 1979.

ZUBEN, F. J. V. \& ATTUX, R. R. F. Árvores de Decisão. Disponível em: ftp://ftp.dca.fee.unicamp.br/pub/docs/vonzuben/ia004_1s10/notas_de_aula/topico7_IA0 04_1s10.pdf. Acesso em: 26 out. 2021.

Recebido em agosto de 2021.

Aprovado em outubro de 2021. 